\title{
AKT inhibition by triciribine alone or as combination therapy for growth control of gastroenteropancreatic neuroendocrine tumors
}

\author{
CHRISTOPH R. GLOESENKAMP ${ }^{1}$, BIANCA NITZSCHE ${ }^{1,2}$, MATTHIAS OCKER $^{3}$, PIETRO DI FAZIO ${ }^{3}$, \\ KARL QUINT $^{3}$, BJÖRN HOFFMANN ${ }^{1}$, HANS SCHERÜBL ${ }^{4}$ and MICHAEL HÖPFNER ${ }^{1}$ \\ ${ }^{1}$ Institute of Physiology, Charité-Universitätsmedizin Berlin, Campus Benjamin Franklin, Thielallee 71, D-14195 Berlin; \\ ${ }^{2}$ Berlin Institute for Urologic Research and Foundation of Urologic Research, Robert-Koch-Platz 7, D-10115 Berlin; \\ ${ }^{3}$ Institute for Surgical Research, Philipps University Marburg, Baldingerstrasse, D-35043 Marburg; \\ ${ }^{4}$ Medical Clinic-Gastroenterology and Gastrointestinal Oncology, Vivantes Klinikum Am Urban, D-10967 Berlin, Germany
}

Received August 6, 2011; Accepted September 21, 2011

DOI: $10.3892 /$ ijo.2011.1256

\begin{abstract}
Up-regulation of phosphatidylinositol-3-kinase (PI3K)-AKT signaling facilitates tumor cell growth and inhibits cell demise. The AKT-pathway also plays an important role in cytostatic therapy resistance and response to hypoxia and angiogenesis. Using real-time cell proliferation assay we examined the potency of triciribine in three distinct neuroendocrine gastrointestinal tumor cell lines. Also we investigated triciribine's induction of apoptosis and effects on a broad range of cancer-associated gene products. Furthermore, we characterized the role of PTEN as a possible predictor of sensitivity to triciribine in GEP-NETs. We also looked for additive anti-neoplastic effects of triciribine when combined with conventional cytostatic drugs or other targeted drugs, affecting different molecules of the PI3K-AKT-pathway and we assessed the potency of triciribine to inhibit tumor growth in vivo, by using the chick chorioallantoic membrane assay. Treatment of insulinoma (CM) or gut neuroendocrine tumor cells (STC-1) with triciribine significantly reduced tumor cell growth by $59 \%$ and $65 \%$, respectively. By contrast, the highly expressing PTEN carcinoid cell line BON did not respond, even at higher doses. Combinations of triciribine with classic cytostatic drugs as well as drugs targeting other molecules of the PI3K-AKT-pathway led to synergistic anti-proliferative effects. Additional in vivoevaluations confirmed the anti-neoplastic potency of triciribine. Thus, our data show that inhibition the AKT-pathway potently reduces the growth of GEP-NET cells alone or in combination therapies. AKT inhibition may provide a rationale for future evaluations.
\end{abstract}

Correspondence to: Dr Michael Höpfner, Institute of Physiology (CBF), Charité-Universitaetsmedizin Berlin, Thielallee 71, D-14195 Berlin, Germany

E-mail: michael.hoepfner@charite.de

Key words: gastroenteropancreatic neuroendocrine tumors, carcinoid, AKT, triciribine, phosphatidylinositol-3-kinase-AKT-pathway, mammalian target of rapamycin, IGF-1R, chick chorioallantoic membrane assay

\section{Introduction}

Gastroenteropancreatic neuroendocrine tumors (GEP-NETs), often synonymously called carcinoids, are a very heterogeneous group of neoplasms. Originally thought of as representing a rather homogeneous group, advances in the knowledge of molecular changes within different tumor entities of the GEP-NETs led to the classification system of the WHO in 2000 (1), later supplemented with additional studies (2).

With a reported incidence of 2-3:100,000 GEP-NETs are relatively rare, but the 5-year survival rate is only about $67 \%$ $(3,4)$. For localized tumors, systemic symptoms can be absent, since often its products, excess biogenic amines and hormones, are mostly cleared by the liver. Metastasized tumors, however, have often incapacitating symptoms, e.g., for the carcinoid syndrome including diarrhea, flushing, wheezing and skin rashes.

The treatment of choice in locally defined tumors is still surgical resection (5). However, at presentation, about $80 \%$ of patients have already developed liver or lymph node metastases. In the advanced stages, the medical treatment options are still poor. Currently, different chemotherapeutic regimens are used, depending amongst others on the differentiation of the tumor, including etoposide plus cisplatin or streptozotocin with 5-FU or doxorubicin (6-8). However, response rates of $0-30 \%$ are still disappointing. In well-differentiated tumors, somatostatin-analogues (lanreotide, octreotide) have been shown to be effective not only in controlling side effects caused by hormone secretion but also in controlling tumor growth (9).

The phosphatidylinositol-3-kinase (PI3K)-AKT signaling pathway has been introduced as an attractive target for cancer therapy, since it is often deregulated in a wide range of tumor types (10-12). Normally, PI3K-AKT signaling plays an important role in cell survival, proliferation, growth and motility. Several PI3K-AKT-associated molecules such as growth factors (e.g., IGF-1, VEGF, EGF or PDGF $\alpha$ ) and related receptors are frequently dysregulated in GEP-NETs (13). Thus, targeting growth factor receptors and the related downstream AKT-pathway has become a rationale for innovative medical treatment of GEP-NETs. This led to clinical studies exploring the effect of targeted drugs such as bevacizumab or sunitinib 
$(14,15)$. Recently, it was shown that the mTOR-inhibitor everolimus significantly prolonged progression-free survival among patients with progressive advanced pancreatic neuroendocrine tumors and was associated with a low rate of severe adverse events (16).

Activated PI3K leads to the recruitment of the serinethreonine protein kinase AKT to the plasma membrane, where it is phosphorylated at residues Thr308 and Ser473 by the phosphoinositide-dependent protein kinase 1 (PDK1) and the mammalian target of rapamycin complex 2 (mTORC2) $(17,18)$. Three isoforms of AKT are known, of which the relative importance of each seems to be cell type-specific (19). The most important inhibitor of AKT-signaling is PTEN (phosphatase and tensin homolog deleted on chromosome 10). PTEN is the second most commonly mutated tumor suppressor gene in cancer (20). Tumors with mutated PTEN are more likely to be resistant against currently used targeted therapies, e.g., the HER2/neu-antibody trastuzumab $(21,22)$. Targeting the PI3K-AKT-pathway directly might be an especially effective approach in PTEN-mutated cancer $(23,24)$.

GEP-NETs often have increased levels of activated, phosphorylated AKT (p-AKT) and show loss of expression of PTEN (13,25-28). Furthermore, for patients with gastrointestinal neuroendocrine tumors, increased pAKT and pAKT: PTEN expression ratios have been shown to be predictive for survival (29).

Several drugs targeting AKT have been developed by now. One of them is the selective small molecule inhibitor triciribine, which inhibits all three isoforms of AKT (30). While for other tumor entities there are already phase I studies on the way $(31,32)$, the efficacy of an AKT-inhibitor for anti-neoplastic treatment in GEP-NETs has not yet been evaluated.

We therefore examined the potency of triciribine in three distinct neuroendocrine gastrointestinal tumor cell lines with different growth characteristics. We investigated triciribineinduced growth inhibition, induction of apoptosis, and effects on a broad range of cancer-associated gene products. We also looked for additive anti-neoplastic effects of triciribine when combined with conventional cytostatic drugs or other targeted drugs, affecting different molecules of the PI3K-AKT-pathway.

\section{Materials and methods}

Cell culture. The human pancreatic BON cell line, established from a human pancreatic carcinoid tumor (33) and the cholecystokinin secreting murine neuroendocrine cell line STC-1 (34) were grown in a 1:1 mixture of DMEM and Ham's F-12 medium containing 10\% (v/v) FCS (Biochrom Co., Berlin, Germany) and $1 \%$ (v/v) L-glutamine. The human insulinoma cell line CM (35), provided by Professor P. Pozzilli (University La Sapienza of Rome, Italy), was cultured in RPMI-1640 supplemented with $10 \%(\mathrm{v} / \mathrm{v})$ FCS (Biochrom) and 1\% L-glutamine. All cell lines were kept at $37^{\circ} \mathrm{C}$ in a humidified atmosphere $\left(5 \% \mathrm{CO}_{2}\right)$.

Drugs. Triciribine was purchased from Merck, Darmstadt, Germany. Doxorubicin and 5-fluorouracil (5-FU) were purchased from Sigma (St. Louis, MO, USA). NVP-AEW541 was from Cayman Chemicals (Ann Harbor, MI, USA) and RAD-001 was purchased from Biomol GmbH (Hamburg, Germany). Stock solutions were prepared in DMSO and stored at $-20^{\circ} \mathrm{C}$; they were diluted to the final concentration in fresh media before each experiment. In all experiments, the final DMSO concentration was $<0.1 \%$.

Impedance-based real-time cell proliferation analysis. Cell viability and proliferation was assessed with the XCELLigence real-time cell analysis system (Roche Molecular Diagnostics, Mannheim, Germany). CM cells $(10,000)$ and BON cells $(20,000)$ were seeded on 96-well E-plates and cell attachment, spreading and proliferation were initially monitored every $15 \mathrm{~min}$ for $24 \mathrm{~h}$. After treatment, measurement intervals were $1 \mathrm{~min}$ for $12 \mathrm{~h}$ and then continuously every $15 \mathrm{~min}$ for further $55 \mathrm{~h}$. Cell proliferation was recorded as arbitrary units (cell index) defined as $\left(\mathrm{R}_{\mathrm{n}}-\mathrm{R}_{\mathrm{b}}\right) / 15 \Omega$ with $\mathrm{R}_{\mathrm{n}}$ being the impedance at time point $n$ and $R_{b}$ being the background impedance of wells containing complete growth medium only.

Measurement of growth inhibition. Drug-induced changes in cell numbers of BON, STC-1 and CM cells were evaluated by crystal violet staining, as described (36). In brief, cells in 96-well plates were fixed with $1 \%$ glutaraldehyde. Then, cells were stained with $0.1 \%(\mathrm{w} / \mathrm{v})$ crystal violet. The unbound dye was removed by washing with water. Bound crystal violet was solubilized with $0.2 \%$ Triton X-100. Light extinction, which increases linearly with the cell number, was analyzed at $570 \mathrm{~nm}$ using an ELISA-Reader. Potential synergy between triciribine and doxorubicin, 5-FU, RAD-001 or NVP-AEW541 was calculated using the method of Chou and Talalay with Calcusyn software (Biosoft, Ferguson, MO, USA) (37). All proliferation assays were performed in triplicate.

Determination of cytotoxicity. Cells were seeded at a density of 4,000 cells/well into 96-well microtitre plates and incubated with rising concentrations of triciribine for 8-24 h. Thereafter, the release of the cytoplasmic enzyme lactate dehydrogenase (LDH), indicating unspecific cytotoxicity, was determined by using a colorimetric kit from Roche as described elsewhere (38). Maximum release of LDH was obtained by adding $100 \mu 12 \%$ (v/v) Triton X-100 to untreated cells. For determinations, $100 \mu \mathrm{l}$ of each sample were incubated with $100 \mu \mathrm{LDH}$ assay reagent for $10 \mathrm{~min}$ at room temperature in the dark. The absorbance of samples was measured at $490 \mathrm{~nm}$. Percentage of LDH release was determined by dividing released LDH of the cells by maximum LDH release multiplied by 100 .

Western blotting. Western blotting was performed as described $(39,40)$. In brief, whole-cell extracts were prepared by lysing cells. Lysates containing $30 \mu \mathrm{g}$ protein were subjected to gel electrophoresis. Proteins were then transferred to PVDF membranes by electroblotting for $1.5 \mathrm{~h}$. Blots were blocked in $5 \%$ skim milk powder solution (Merck) for $1 \mathrm{~h}$, and incubated at $4^{\circ} \mathrm{C}$ overnight with antibodies directed against AKT, pAKT and PTEN (1:1,000; Cell Signaling, MA, USA) as well as with anti-human cyclin D1 (1:2,000; Santa Cruz Biotechnology, CA, USA). After incubation with horseradish peroxidase-coupled anti-IgG antibodies (1:10,000; Amersham, Uppsala, Sweden) at room temperature for at least $1 \mathrm{~h}$, the blot was developed using enhanced chemiluminescent (ECL) detection (Amersham) and subsequently exposed to Hyperfilm ECL film (Amersham) for 0.5-10 $\mathrm{min}$. Experiments were performed three times, and representative experiments are shown. 
Reverse transcription-polymerase chain reaction (RT-PCR). Total RNA was extracted with RNeasy Mini Kit (Qiagen, Hilden, Germany) following the manufacturer's instructions. Concentration and purity were measured by absorption spectrophotometry (GeneQuant, Biochrom, Cambridge, UK) at 260 and $280 \mathrm{~nm}$. The cDNA was synthesized from $2 \mu \mathrm{g}$ of total RNA using the Superscript RT kit (Invitrogen, Carlsbad, CA, USA) according to the manufacturer's protocol. The sequences of PTEN primer pair were: PTEN (forward, 5'-CCAATGTTCAGTGGCGGAACT-3'; reverse, 5'-GAACTT GTCTTCCCGTCGTGTG-3') (41). Reverse transcriptase-PCR was carried out in a total volume of $50 \mu \mathrm{l}$ containing $200 \mathrm{nmol} / \mathrm{l}$ of each primer, $200 \mu \mathrm{mol} / 1 \mathrm{dNTPs}$ (Invitrogen), $1.5 \mathrm{mM} \mathrm{MgCl}_{2}$ and $2 \mathrm{U}$ aTaq DNA-polymerase (Promega, Madison, WI, USA). The PCR was performed in a Peltier thermal cycler (PTC-200, MJ-Research, USA) with the primers described above.

DNA microarray (84 cancer pathway-specific genes). Total cellular RNA was extracted from cells using ArrayGrade Total RNA Isolation Kit (SABiosciences, Frederick, MD, USA). RNA was quantified by spectrophotometer (GeneQuant, Biochrom). The True-Labelling AMP 2.0 amplification kit (SABiosciences) was used for transcription of mRNA into cDNA, which was then converted into biotin-labelled cRNA using biotin-16-UTP (Roche) via in vitro transcription. Before hybridization, the cRNA probes were purified with an ArrayGrade cRNA cleanup kit (SABiosciences). The purified cRNA probes were then hybridized to the pre-treated Oligo GEArray Human Cancer Pathway Finder array (OHS-033, SABiosciences). After washing steps, array spots binding cRNA were detected by the chemiluminescence method according to the manufacturer's procedure. Image acquisition was performed using X-ray film and digital scanner. Spots were analysed and converted to numerical data by using the GEArray Expression Analysis Suite software (SABiosciences). Data evaluation included background correction (subtraction of minimum value) and normalization to reference genes. The cut-off for up-regulation was set at a 1.4-fold increase of the ratio of genes in the treated samples, whereas down-regulation was determined as the 0.8 -fold expression of genes in the treated samples.

Migration assay. CM cells were allowed to grow into full confluence in 6-well plates. The monolayer was then scratched with a $10-\mu 1$ pipette tip. Fresh growth medium was added and different concentrations of triciribine were added. Images were taken with Kappa digital camera after $24 \mathrm{~h}$ of incubation at $37^{\circ} \mathrm{C}$ in a humidified atmosphere of $5 \% \mathrm{CO}_{2}$. The migrated cells were quantified by using the software TScratch (42).

Annexin V-FITC assay. Apoptosis was monitored by detection of Annexin $\mathrm{V}$ expression on the outer leaflet of the cell membrane, which is an early event in the apoptotic cascade, using the apoptosis detection kit (Pharmingen, CA, USA). Briefly, the cells grown on slides were treated with different concentrations of triciribine and $48 \mathrm{~h}$ later were washed with PBS. Then the cells were incubated for $30 \mathrm{~min}$ at $22-25^{\circ} \mathrm{C}$ with FITC-conjugated Annexin V incubation reagent [containing $1 \mu \mathrm{g} / \mathrm{ml}$ Annexin V-biotin and $2 \mu \mathrm{mol} / 1$ ethidium bromide (EB)]. After washing again with PBS, cells were examined using fluorescence microscopy. Cells negative for both EB and
Annexin V staining were defined as living and healthy cells; EB-negative but Annexin V-positive staining cells reflected early apoptotic cells, while cells positive for both EB and Annexin V were regarded as secondary necrotic cells (initially apoptotic and then necrotic) $(43,44)$.

Cell cycle analysis/apoptotic cell death by flow cytometry. Cell cycle analysis was performed by a modified method of Fried et al (45). Cells were seeded at a concentration of $10^{5}$ cells $/ \mathrm{ml}$ and treated with triciribine for $24 \mathrm{~h}$. Cells were then washed with PBS and fixed in PBS/2\% (vol/vol) formaldehyde on ice for $30 \mathrm{~min}$. Afterwards cells were incubated in ethanol/PBS (2:1 vol/vol) for $30 \mathrm{~min}$ and pelleted. Resuspension in PBS containing $40 \mu \mathrm{g} / \mathrm{ml}$ RNase A followed. After incubation for $30 \mathrm{~min}$ at $37^{\circ} \mathrm{C}$, cells were pelleted again and resuspended in PBS containing $50 \mu \mathrm{g} / \mathrm{ml}$ propidium iodide. Cells were then analyzed on a FACSCalibur flow cytometer using CellQuestPro Software (BD Biosciences, Heidelberg, Germany) and FlowJo Software (Tree star, Ashland, OR). Apoptotic cells can be identified as a hypoploid cell population commonly called 'subG1' (46).

Chick chorioallantoic membrane (CAM) angiogenesis assay. CAM assay was done as described previously (47). Briefly, $2.5 \times 10^{6} \mathrm{CM}$ cells were resuspended in $20 \mu \mathrm{l}$ growth medium and mixed with $30 \mu 1$ growth factor reduced Matrigel (BD Biosciences). The cell suspensions were implanted on the CAM on day 10 of chick embryo development. After two days, tumors were formed and topically treated once with $20 \mu \mathrm{M}$ triciribine in $100 \mu 1$ PBS. The control group was treated with PBS. Tumor growth and viability of the embryo were controlled daily for $72 \mathrm{~h}$ by stereo microscopy. At the end of experiments, tumors were recovered and pictures were taken using a stereomicroscope equipped with a Kappa digital camera system.

\section{Results}

Triciribine-mediated growth inhibition. In this study, we explored the anti-tumor activity of AKT inhibition by monitoring cell response to triciribine in gastroenteropancreatic neuroendocrine tumor cells, using a real-time cell analysis system (xCELLigence). This system continuously monitors live cells in response to the exposure of triciribine and provides kinetic information from the cell population. The normalized cell index (CI) is an arbitrary unit derived from electrical impedance measurement and correlates with cell viability. Dose- and time-dependent cell responses to triciribine were clearly shown in tumor cell line CM (Fig. 1A), whereas no appreciable cell response was observed in the cell line BON (Fig. 1B). To confirm these effects, changes in cell number caused by triciribine were additionally studied by crystal violet assays. In serum-containing medium, triciribine time- and dose-dependently inhibited the growth of fast growing CM cells (doubling time $21 \pm 1 \mathrm{~h}$ ). After $96 \mathrm{~h}$ of incubation with $0-20 \mu \mathrm{mol} / 1$ triciribine, a decrease in cell number of $>65 \%$ was observed (Fig. 1C). However, in moderate growing BON cells (doubling time $34 \pm 4 \mathrm{~h}$ ), there was no growth inhibition at doses as high as $50 \mu \mathrm{mol} / \mathrm{l}$, and only a meager inhibition of about $18 \%$ at very high doses of $75 \mu \mathrm{mol} / 1$ triciribine after $48 \mathrm{~h}$. This initial effect wore off to $7 \%$ after $96 \mathrm{~h}$ (Fig. 1D). Treatment 

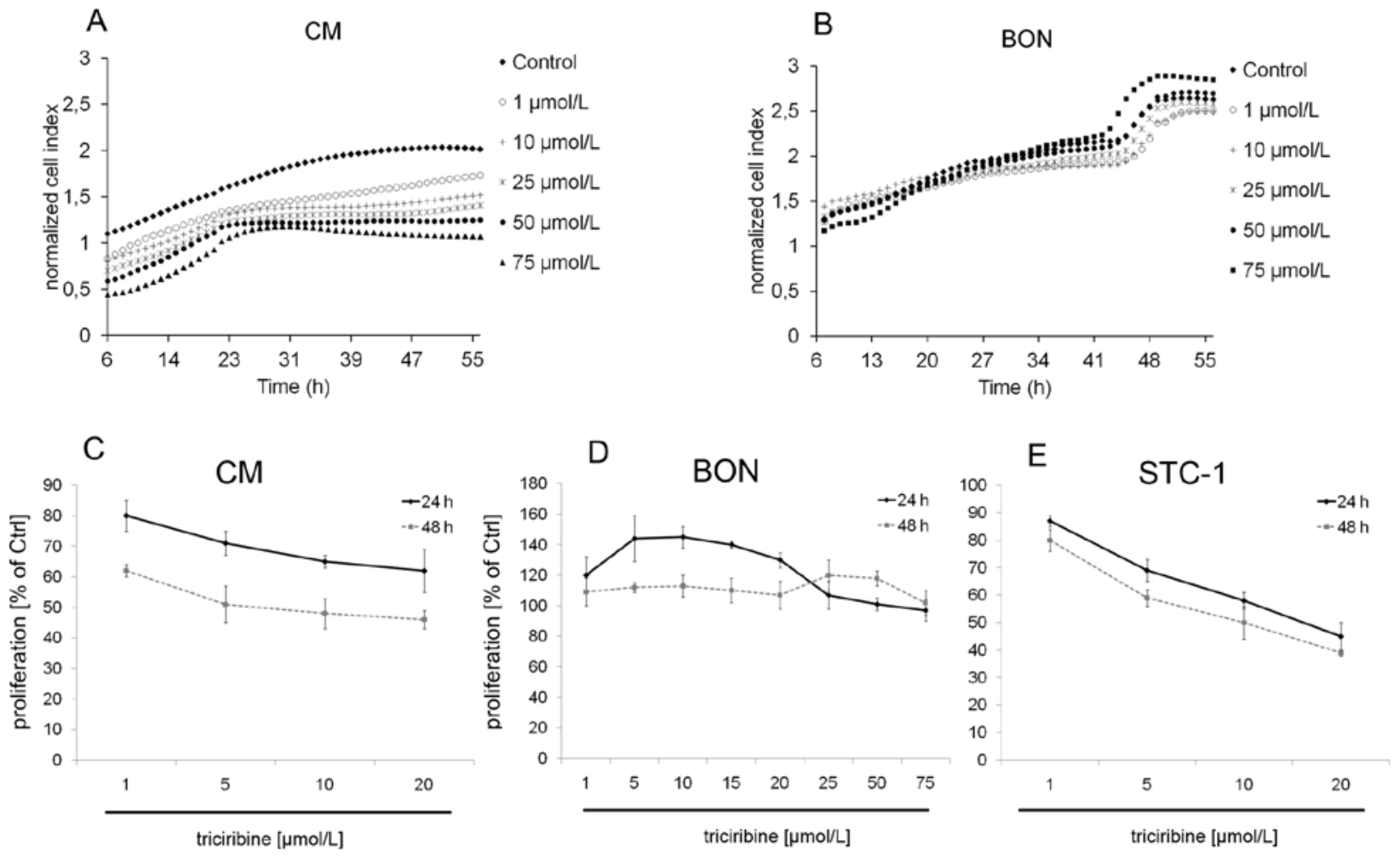

Figure 1. Triciribine reduces cell growth. Cellular growth was monitored and recorded every hour for at least $55 \mathrm{~h}$ in CM and BON cells that were treated with increasing concentrations of triciribine. The x-axis is time in hours after treatment. The y-axis shows the normalized CI. This is an arbitrary unit derived from electrical impedance measurement and correlates with cell proliferation. Triciribine showed profound growth inhibition only in the CM cells (A), but not in the BON cells (B). Also, this inhibition was measured by crystal violet staining. The growth of CM cells was inhibited $>60 \%$ after $96 \mathrm{~h}$ (C) and in BON cells only a slight growth inhibition of $18 \%$ was observed (D). In the neuroendocrine tumor cells STC-1 there was a growth inhibition of $>55 \%$ (E). Data are given as percentage of untreated controls (means \pm SEM of at least 3 experiments).

of STC-1 cells, representing a slow growing neuroendocrine gastrointestinal tumor cell line (doubling time $54 \pm 6 \mathrm{~h}$ ), led to a growth inhibition of $>55 \%$ (Fig. 1E).

Cytotoxic effects of triciribine. Non-specific cytotoxicity was evaluated by cellular LDH release into the culture medium. Incubating CM cells with $0-20 \mu \mathrm{mol} / \mathrm{l}$ for up to $24 \mathrm{~h}$ did not result in a significant increase in $\mathrm{LDH}$ release, indicating that triciribine does not directly affect cell membrane integrity and does not have immediate toxic effects even at concentrations, which led to pronounced growth inhibitory effects. Similar results were obtained with STC-1 cells. Expectedly, no cytotoxic effect of triciribine was observed in the non-responding BON cells either (data not shown).

Triciribine inhibited phosphorylation of AKT and cyclin DI in gastrointestinal neuroendocrine tumor cells. The three cells lines were treated with triciribine (0-20 $\mu \mathrm{mol} / \mathrm{l})$ for $48 \mathrm{~h}$. As a marker of AKT activation, we measured phosphorylation of AKT at serine 473. In CM- and STC-1 cells, levels of p-AKT were dose-dependently decreased. The cell cycle regulator cyclin D1 is known to be up-regulated by p-AKT. We therefore looked for changes in cyclin D1 levels in triciribine treated GEP-NET cells. Proportionally to changes in activated $\mathrm{AKT}$, there was also a dose-dependent decrease in cyclin D1 in CM- and STC-1 cells (Fig. 2A and B). Interestingly, also in BON cells a dose-dependent decrease in phosphorylated-
AKT was observed, but in contrast to CM and STC-1 cells an associated decrease in cyclin D1 expression did not occur (Fig. 2C).

AKT inhibition changed the expression of various cancerassociated genes. Effects of triciribine treatment on the expression of cancer-associated genes were investigated by performing a cancer pathway gene array (Table I). CM cells were treated with $20 \mu \mathrm{mol} / \mathrm{l}$ triciribine for $48 \mathrm{~h}$ and alterations in gene expression was compared to untreated control cells, yielding a marked regulation of 48 genes.

Cell cycle arrest-related genes. Cyclin E and cyclin-dependent kinase 2 (CDK2), important for the G1/S-phase transition, are down-regulated after triciribine treatment. CDK4, which is influencing the G0/S-phase transition, was also down-regulated. The CDK inhibitors p21, p27 as well as p16, inhibitors of G0/ S-phase transition, were up-regulated. Triciribine treatment also led to a down-regulation of E2F transcription factor 1 (E2F1), a regulator of the expression of several proteins involved in cell cycle progression.

Apoptosis and senescence-related genes. V-akt was downregulated and PTEN the main inhibitor of AKT was up-regulated. Moreover, other apoptosis inducing genes, such as APAF1 and BAX were up-regulated and the anti-apoptotic gene BIRC5 (survivin) was down-regulated. Surprisingly, the expression of PIK3R1, which is an important inhibitor of PI3K and a potential oncogene, was also down-regulated. 


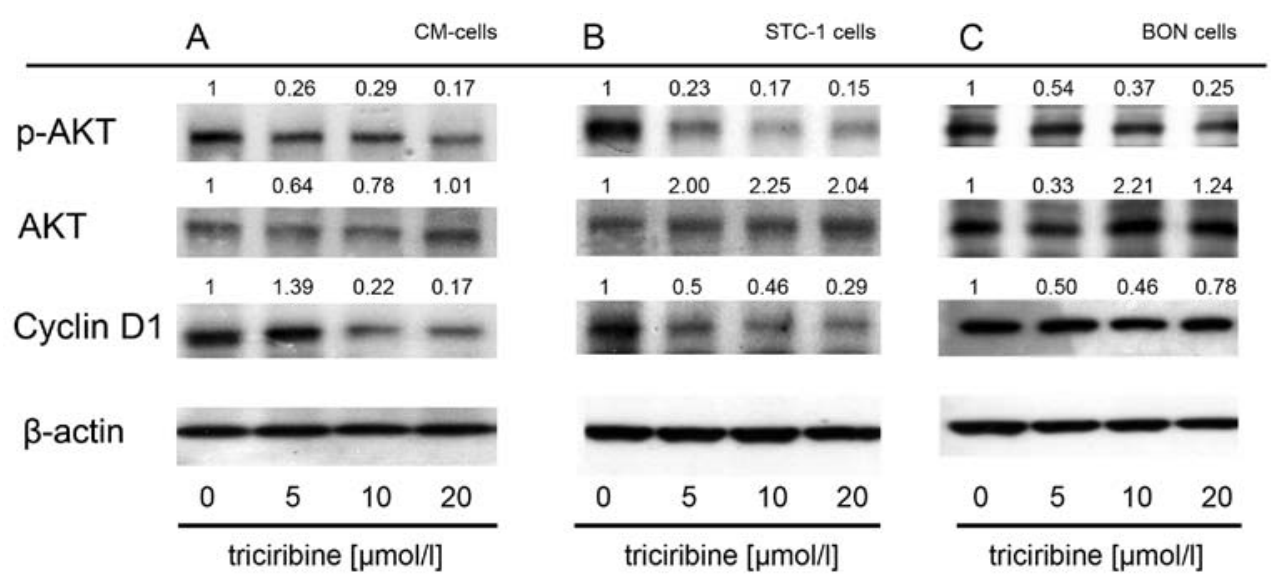

Figure 2. Triciribine changes levels of p-AKT and cyclin D1 in GEP-NETs. Changes in protein concentrations after triciribine treatment in GEP-NETs were evaluated by Western blotting. Densitometry was performed using ImageJ. Numbers above the bands indicate the relative-fold increase or decrease in triciribine treated cells compared to untreated cells. Protein levels in untreated cells was set as 1, the following concentrations in triciribine treated cells indicates the relative changes. Cells were grown in serum containing medium and treated with increasing doses of triciribine for $48 \mathrm{~h}$. (A and B), Phosphorylation of AKT and levels of cyclin D1, an effector protein of AKT, decreased dose-dependently, while overall levels of AKT remained unchanged in CM and STC-1 cells. (C), In BON cells there was also a dose-dependent decrease in phosphorylated AKT, while this could not be observed when measuring protein levels of cyclin D1.

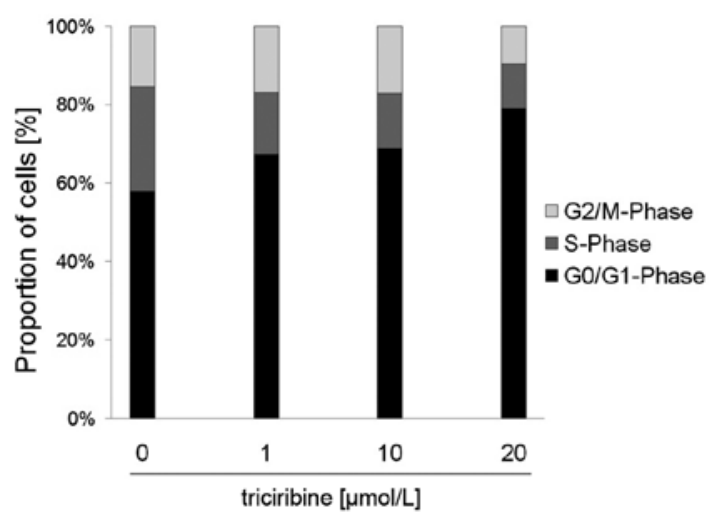

Figure 3. Triciribine-induced cell cycle arrest in GEP-NET cells. Twenty-four hour incubation of CM cells with increasing doses of triciribine led to an accumulation of cells in G0/G1-phase. The amount of cells in S- or G2/M-phase decreased proportionally (means of 3 experiments, SEM not shown).

Proapoptotic effects of triciribine. To further investigate the role of apoptosis in the observed anti-neoplastic effects of triciribine, we analyzed cell membrane binding to Annexin V, which serves as a marker of early apoptosis. After $48 \mathrm{~h}$ of incubation with $0-20 \mu \mathrm{mol} / 1$ of triciribine a dose-dependent increase in apoptosis-specific Annexin V staining became apparent. Albeit to a small degree only, there were also additional signs of late apoptosis as indicated by the simultaneous staining of cells with propidium iodide (data not shown). Moreover, flow cytometry revealed a moderate induction of apoptosis after $48 \mathrm{~h}$ in cells treated with triciribine as indicated by the 'subGl' cell population. At $20 \mu \mathrm{mol} / 1$ triciribine the amount of apoptotic cells increased about 3 -fold (data not shown). Together with the above-described changes in the expression pattern of several pro-apoptotic and anti-apoptotic genes (Table I) the data suggest that the anti-neoplastic effects of triciribine in GEP-NET cells are at least partially due to an induction of apoptosis.

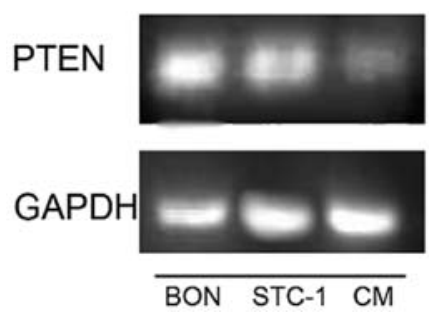

Figure 4. Gene expression of PTEN in different cell lines. mRNA levels of PTEN in GEP-NET cell lines were evaluated by RT-PCR. Highest levels of PTEN expression were found in BON cells, while those in CM cells were rather low, roughly correlating with sensitivity to triciribine treatment.

AKT inhibition and cell cycle arrest. Since the PI3K-AKTpathway is known to modulate the cell cycle leading to cell cycle progression, we investigated the effect of triciribine on the cell cycle of GEP-NET cells using flow cytometry. Triciribine led to a dose-dependent increase in the G0/G1-phase while the amount of cells in S- and G2/M-phase decreased, indicating cell cycle arrest (Fig. 3). Together with the above-mentioned downregulation of several cell cycle-promoting genes (Table I), we could clearly demonstrate that also an induction of cell cycle contributes to the anti-neoplastic mode of action of triciribine in GEP-NET cells.

Correlation of PTEN and efficacy of triciribine. To check out the possible correlation of growth inhibition and the expression of PTEN in the different GEP-NET cell lines, RT-PCR was performed (Fig. 4). While triciribine-sensitive CM cells showed the lowest expression of PTEN, the PTEN expression in triciribine insensitive BON cells was very pronounced. Respective Western blots revealed a cell line-specific expression of PTEN, which was not altered by triciribine treatment (data not shown). Our data confirm the notion that PTEN expression markedly influences the sensitivity of GEP-NET cells to triciribine treatment. 
Table I. Transcripts differentially regulated in CM cells in response to triciribine.

Up- and down-regulated genes

Symbol

Product

Fold

Apoptosis

APAF1

Apoptotic peptidase activating factor 1

8.84

BAX

BCL2-associated $X$ protein

13.52

BIRC5

Baculoviral IAP repeat-containing 5 (survivin)

0.30

FAS

Fas (TNF receptor superfamily, member 6)

2.56

TERT

Telomerase reverse transcriptase

1.49

TNFRSF1A

Tumor necrosis factor receptor superfamily, member $1 \mathrm{~A}$

0.68

Cell cycle related genes

BRCA1

Breast cancer 1, early onset

CCNE1

Cyclin E1

0.17

CDK2

Cyclin-dependent kinase 2

0.57

CDK4

Cyclin-dependent kinase 4

0.68

CDKN1A

Cyclin-dependent kinase inhibitor 1B (p27, Kip1)

2.33

CDKN1B

Cyclin-dependent kinase inhibitor 1A (p21, Cip1)

1.40

CDKN2A

Cyclin-dependent kinase inhibitor 2A (melanoma, p16, inhibits CDK4)

1.84

$\mathrm{E} 2 \mathrm{~F} 1$

E2F transcription factor 1

0.04

PTEN

Phosphatase and tensin homolog

5.56

TP53

Tumor protein p53 (Li-Fraumeni syndrome)

Signal transduction molecules and transcription factors

AKT1

ERBB2

MAP2K1

NFKBIA

PIK3R1

SNCG

SRC

Adhesion

CD44

EPDR1

ITGA3

ITGB1

ITGB5

MCAM

NCAM1

PNN

Angiogenesis

IGF-1

IL8

PDGFA

PDGFB

TGFBR1

THBS 1

THBS2
V-akt murine thymoma viral oncogene homolog 1

0.18

V-erb-B2 erythroblastic leukemia viral oncogene homolog 2

0.79

Mitogen-activated protein kinase kinase 1

0.72

Nuclear factor of kappa light polypeptide gene enhancer in B-cells

1.70

Phosphoinositol-3-kinase, regulatory subunit 1 (p85 alpha)

0.24

Synuclein, gamma (breast cancer-specific protein 1)

4.87

V-src sarcoma (Schmidt-Ruppin A-2) viral oncogene homolog (avian)

CD44 molecule (Indian blood group)

4.98

Ependymin related protein 1 (zebrafish)

0.43

Integrin, alpha 3 (antigen CD49C, alpha 3 subunit of VLA-3 receptor)

1.63

Integrin, beta 1

0.70

Integrin, beta 5

0.71

Melanoma cell adhesion molecule

0.76

Neural cell adhesion molecule 1

0.56

Pinin, desmosome associated protein

0.76

Insulin-like growth factor-1 (somatomedin C)

Interleukin 8

33.59

Platelet-derived growth factor alpha polypeptide

9.70

Platelet-derived growth factor beta polypeptide

8.03

Transforming growth factor, beta receptor I

Thrombospondin 1

Thrombospondin 2 
Table I. Continued.

Up- and down-regulated genes

Symbol

Product

Fold

Invasion and metastasis

\begin{tabular}{lll} 
CD82 & CD82 molecule & 4.09 \\
KISS1 & KiSS-1 metastasis-suppressor & 4.82 \\
MMP1 & Matrix metallopeptidase 1 (interstitial collagenase) & 18.32 \\
MMP2 & Matrix metallopeptidase 2 & 1.93 \\
NME1 & Non-metastatic cells 1, protein (NM23A) expressed in & 0.69 \\
NME4 & Non-metastatic cells 4, protein expressed in & 0.65 \\
PLAU & Plasminogen activator, urokinase \\
PLAUR & Plasminogen activator, urokinase receptor \\
TIMP1 & TIMP metallopeptidase inhibitor 1 \\
TIMP3 & TIMP metallopeptidase inhibitor 3 & 4.88 \\
\hline
\end{tabular}

Analysis of signal intensity of each gene and global normalization was performed with GEArray Expression Analysis Suite. We compared gene expression in untreated and triciribine treated $\mathrm{CM}$ cells. The ratio describes the magnitude of changes in gene expression after triciribine treatment. As a cut-off we chose ratio values of higher than 1.4 for up-regulated genes and lower than 0.8 for down-regulated genes. Of the 113 analyzed genes known to be cancer associated, 28 genes were up-regulated and 20 genes were down-regulated.

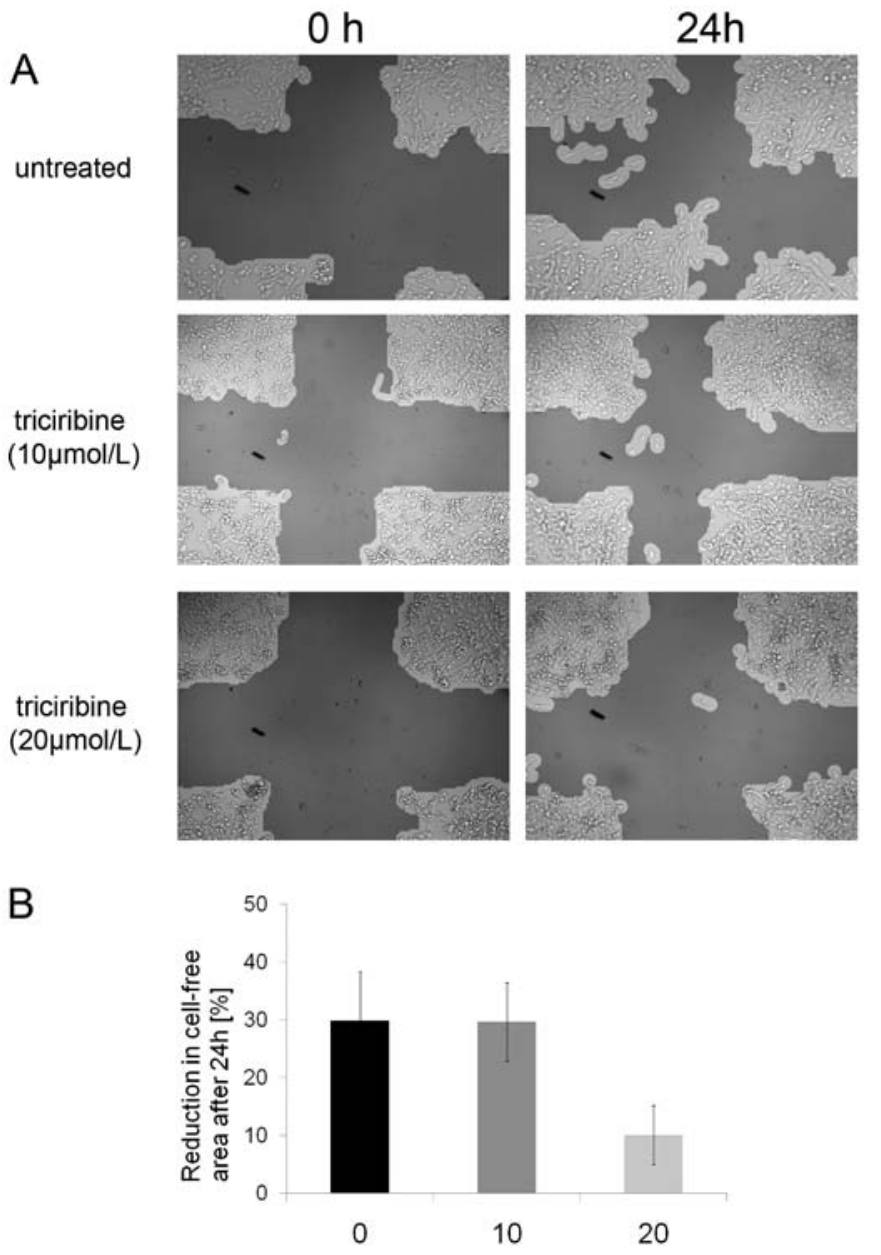

Figure 5. Triciribine inhibited the migration of CM cells. (A), Images of CM cell migration assay. Light grey areas are cell covered surfaces; dark grey represents wounded areas with no cells. Cells were treated with increasing doses of triciribine. (B), Diminished scar surface quantified by the software TScratch. In the presence of triciribine, fewer cells moved into the scarred region, reflected by less covering of surface in the area of the scar (means \pm SEM of at least 3 experiments).
A

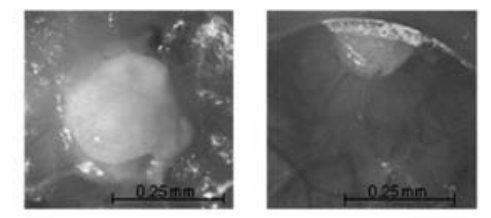

B

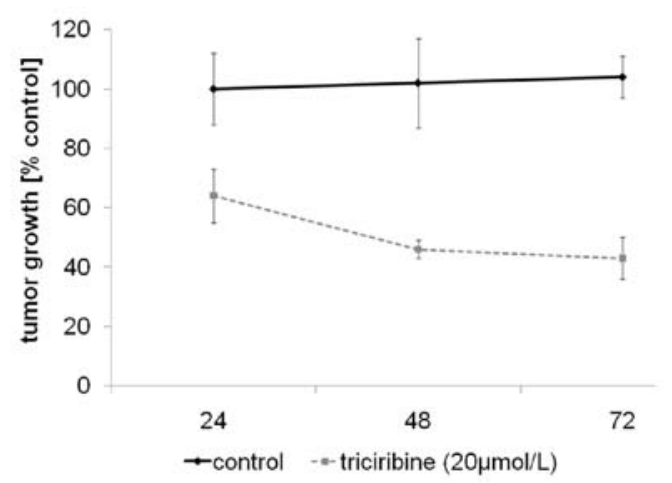

Figure 6. Effects of triciribine on neuroendocrine tumors of CM cells in the CAM assay. CAM assay was performed to analyze the effects of triciribine in vivo. Tumor cells, $2.5 \times 10^{6}$, were resuspended in $20 \mu \mathrm{l}$ medium and $30 \mu \mathrm{l}$ Matrigel matrix and implanted on fertilized chicken eggs at day 10 of development. Tumors were topically treated once with $20 \mu \mathrm{mol} / \mathrm{l}$ triciribine in $100 \mu \mathrm{l}$ PBS then grown tumors were photographed for $72 \mathrm{~h}$. (A), Representative images of CM tumors after $96 \mathrm{~h}$ of treatment. (B), Calculated tumor volumes of treated CM tumors compared to control tumors.

Changes in migration induced by triciribine. Scratch assays were used to examine the effect of triciribine on neuroendocrine tumor cell migration. $\mathrm{CM}$ cells were treated with increasing doses of triciribine for $24 \mathrm{~h}$, which markedly decreased the migration of GEP-NET cells as compared to the untreated control cells (Fig. 5). 
Triciribine inhibits in vivo tumor growth as assessed by the chicken CAM assay. The anti-neoplastic effect of triciribine on GEP-NET growth was additionally evaluated in vivo. Therefore, CM cells were inoculated into the chicken chorioallantoic membrane of 10-day-old chick embryos. The inoculated $\mathrm{CM}$ cells formed macroscopic tumors in each case. After 3 days of incubation with triciribine $(20 \mu \mathrm{mol} / \mathrm{l})$ either macroscopically evaluation (Fig. 6A) or mathematical calculation of tumor volumes (Fig. 6B) revealed that triciribine markedly inhibited GEP-NET tumor growth $>50 \%$, as compared to the untreated control tumors.

Anti-neoplastic potency of triciribine in combination with other drugs. To look for possible additive or even synergistic effects of combination treatment of GEP-NET cells with triciribine, we used cytostatic drugs, which are already established for medical treatment of GEP-NETs. CM- and STC-1 cells were treated with $5 \mu \mathrm{mol} / 1$ triciribine as well as increasing doses of either doxorubicin or 5-FU. When given as a single drug both 5-FU and doxorubin led to dose-dependent growth inhibition of $\mathrm{CM}$ and STC-1 cells (Fig. 7). Results of combination treatment of the drugs together with triciribine were analyzed with Calcusyn software. Triciribine synergistically enhanced the anti-proliferative effect of doxorubicin, although this was only slightly pronounced. On the other hand combinations of triciribine and 5-FU were at least moderately synergistic (Table II).

Additional combinations of triciribine together with an mTORC1 inhibitor (RAD-001), or an IGF-1R inhibitor (NVPAEW541) were also investigated (Fig. 8). Both combinations were strongly synergistic in both $\mathrm{CM}$ and STC-1 cells. The combination of NVP-AEW541 and triciribine showed the strongest synergism of all the tested combinations (Table II).

\section{Discussion}

Due to the use of established drugs such as somatostatin analogues, great progress has been made in controlling the often debilitating hypersecretion syndrome encountered in patients with metastasized GEP-NETs (48). However, current cytostatic therapy regimens aiming at slowing tumor progression or even inducing remission are so far of only limited success $(6,7)$. The PI3K-AKT-pathway is known to be important in tumor survival and progression when deregulated (10-12). Furthermore, GEP-NETs often show an overly active AKT and PTEN mutations, the most important suppressor protein of the PI3K-AKT-pathway (26-29). There are some publications looking at the effect of pharmacologic inhibition of PI3K in carcinoid cells as well as inhibiting the isozyme AKT1 using siRNA in vitro $(49,50)$. However, the observed effects were only moderate and high doses of inhibitors had to be employed. Furthermore, the observations were restricted to single cell line experiments. So far, there are no publications looking at the effects of pharmacologically inhibiting AKT in neuroendocrine tumor cell lines.

In this study, we showed that inhibition of all three isoforms of AKT by triciribine may become a promising approach for novel treatment options in GEP-NETs. By using the impedance based measurement of cell proliferation we could show that the pan-AKT inhibitor triciribine (30) led to a time- and dose-dependent reduction in cell growth of GEP-NET cells.
Table II. Comparison of synergistic effects of triciribine in combination with other chemotherapeutics.

\begin{tabular}{|c|c|c|c|c|}
\hline & $\begin{array}{l}\text { Doxorubicin } \\
\quad(\mathrm{nmol} / \mathrm{l})\end{array}$ & $\begin{array}{l}\text { Triciribine } \\
(\mu \mathrm{mol} / \mathrm{l})\end{array}$ & $\mathrm{Fa}$ & $\mathrm{CI}$ \\
\hline \multirow[t]{3}{*}{ CM cells } & 50 & 5 & 0.75 & 0.989 \\
\hline & 100 & 5 & 0.91 & 0.559 \\
\hline & 200 & 5 & 0.93 & 0.845 \\
\hline \multirow[t]{4}{*}{ STC-1 cells } & 50 & 5 & 0.58 & 0.734 \\
\hline & 100 & 5 & 0.72 & 0.656 \\
\hline & 200 & 5 & 0.88 & 0.705 \\
\hline & $\begin{array}{c}5-\mathrm{FU} \\
(\mu \mathrm{mol} / \mathrm{l})\end{array}$ & $\begin{array}{c}\text { Triciribine } \\
(\mu \mathrm{mol} / \mathrm{l})\end{array}$ & $\mathrm{Fa}$ & CI \\
\hline \multirow[t]{3}{*}{$\mathrm{CM}$ cells } & 2.5 & 5 & 0.69 & 0.256 \\
\hline & 5 & 5 & 0.71 & 0.341 \\
\hline & 10 & 5 & 0.73 & 0.463 \\
\hline \multirow[t]{4}{*}{ STC-1 cells } & 1.25 & 5 & 0.6 & 0.349 \\
\hline & 2.5 & 5 & 0.62 & 0.402 \\
\hline & 5 & 5 & 0.64 & 0.496 \\
\hline & $\begin{array}{l}\text { Everolimus } \\
\text { (nmol/l) }\end{array}$ & $\begin{array}{l}\text { Triciribine } \\
(\mu \mathrm{mol} / \mathrm{l})\end{array}$ & $\mathrm{Fa}$ & $\mathrm{CI}$ \\
\hline \multirow[t]{3}{*}{ CM cells } & 25 & 5 & 0.66 & 0.309 \\
\hline & 50 & 5 & 0.78 & 0.325 \\
\hline & 100 & 5 & 0.87 & 0.384 \\
\hline \multirow[t]{4}{*}{ STC-1 cells } & 25 & 5 & 0.7 & 0.245 \\
\hline & 50 & 5 & 0.7 & 0.341 \\
\hline & 100 & 5 & 0.72 & 0.421 \\
\hline & $\begin{array}{l}\text { NVP-AEW541 } \\
(\mu \mathrm{mol} / \mathrm{l})\end{array}$ & $\begin{array}{c}\text { Triciribine } \\
(\mu \mathrm{mol} / \mathrm{l})\end{array}$ & $\mathrm{Fa}$ & CI \\
\hline \multirow[t]{3}{*}{ CM cells } & 2.5 & 1 & 0.89 & 0.388 \\
\hline & 2.5 & 5 & 0.95 & 0.285 \\
\hline & 2.5 & 10 & 0.97 & 0.235 \\
\hline \multirow[t]{3}{*}{ STC-1 cells } & 2.5 & 1 & 0.67 & 0.169 \\
\hline & 2.5 & 5 & 0.81 & 0.095 \\
\hline & 2.5 & 10 & 0.91 & 0.037 \\
\hline
\end{tabular}

$\mathrm{CI}<0.9$ denotes slight synergistic effects of two agents, $<0.7$ synergistic effects, $<0.3$ strong synergistic effects. CI 0.9-1.1 denotes an additive relationship. CI $>1.1$ denotes antagonism. Synergy was assessed using the method of Chou et al (37) with Calcusyn software. Proliferation assays were performed in triplicate. The data are derived from a representative experiment; studies were performed three times. Fa, fraction of cells affected by treatment; CI, combination index.

The normalized CI is an arbitrary unit derived from electrical impedance measurement and correlates with the cell viability (51). The growth inhibitory activity results from an induction of the cell cycle and/or apoptosis. At least in CM and STC-1 cells the anti-proliferative effects correlated with the reduction in protein levels of phosphorylated AKT and one of its 

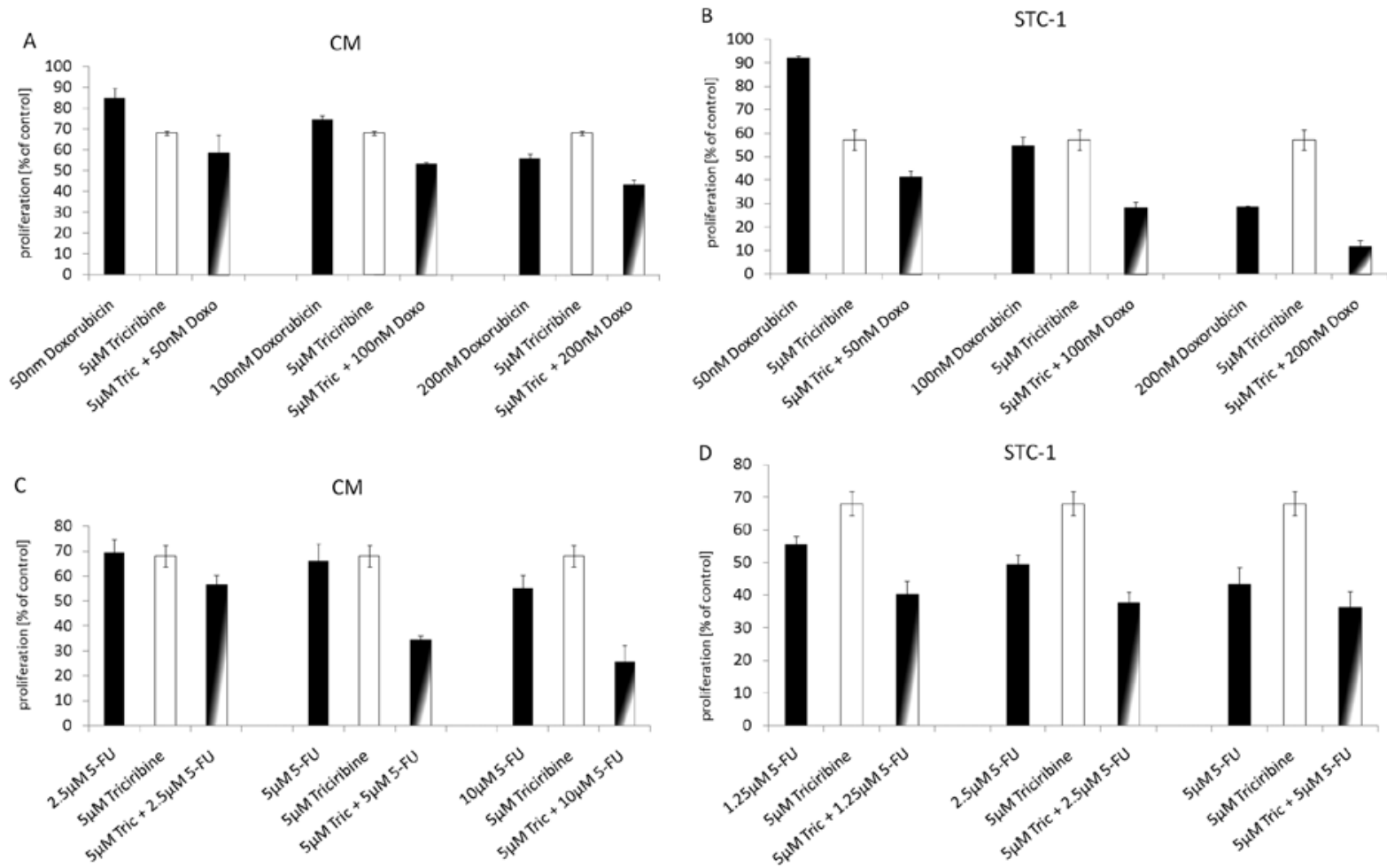

Figure 7. Anti-proliferative effects of combination treatment with triciribine plus doxorubicin or 5-FU. Forty-eight hour incubation with doxorubicin (0-200 $\mathrm{nM})$ led to a dose-dependent growth inhibition of (A) $\mathrm{CM}$ and (B) STC-1 cells by $>40 \%$ (CM) and $>55 \%$ (STC-1). Combination treatment $\left(48 \mathrm{~h}\right.$ ) of a sub-IC ${ }_{50}$ concentration of triciribine $(5 \mu \mathrm{M})$ plus doxorubicin led to slight synergistic growth inhibition effects in both cell lines (Table I). (C), Incubation with 5-FU (0-10 $\mu \mathrm{M})$ for $48 \mathrm{~h}$ led to a dose-dependent growth inhibition of CM cells. Combination with triciribine resulted in moderate to strong synergistic growth inhibition. (D), In STC-1 cells combination treatment of 5-FU and triciribine also led to moderate growth inhibitory synergism. All experiments were performed in serumcontaining media. Data are given as percentage of untreated controls (means \pm SEM of 3 experiments).

A
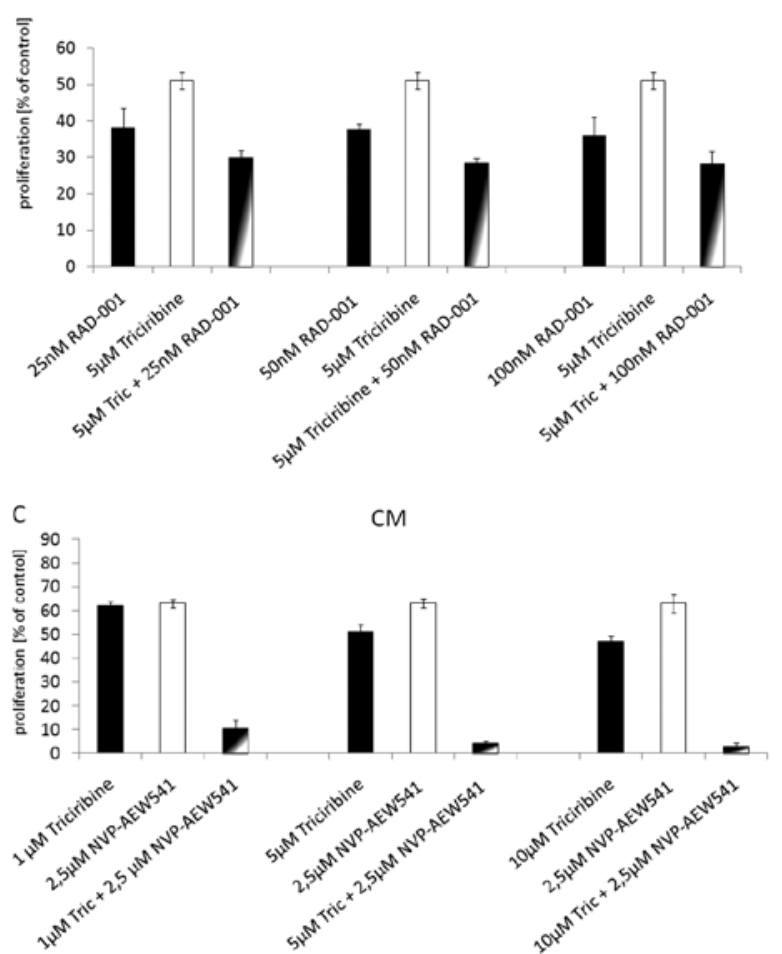

B
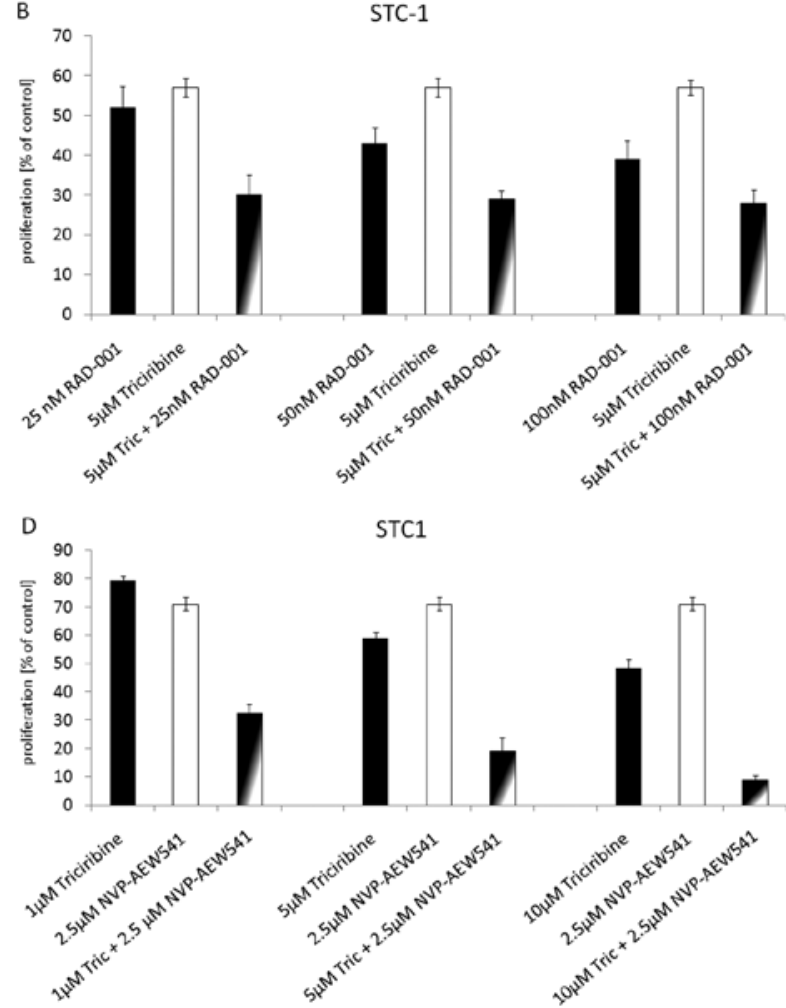

Figure 8. Anti-proliferative effects of combination treatment with triciribine and RAD-001 or NVP-AEW541. Incubation of CM (A) and STC-1 (B) cells with RAD-001 (0-100 nM) led to a dose-dependent growth inhibition of $>60 \%$ in both cell lines. Combination treatment with sub-IC $_{50}$ concentrations of triciribine and RAD-001 showed moderate synergistic growth inhibition (Table I). Incubation of CM (C) and STC-1 (D) cells with NVP-AEW541 (2.5 $\mu$ M) led to a growth inhibition of about 50\% in either cell line. Combination treatment of NVP-AEW541 and rising concentrations of triciribine resulted in strong synergistic growth inhibition in both CM and STC-1 cells. All experiments were performed in serum-containing media. Data are given as percentage of untreated controls (means \pm SEM of 3 experiments). 
regulated proteins, the cell cycle promoter cyclin D1 $(52,53)$. Since GEP-NETs are very heterogeneous and differ from slow growing to fast growing aggressive tumors (1), it is important to look at different representatives of this tumor entity when testing new therapeutic agents.

We therefore chose three cell lines with different growth rates and origins: human insulinoma $\mathrm{CM}$ cells are the fastest growing cells in our study with a doubling time of $21 \mathrm{~h}$; human pancreatic carcinoid BON cells (doubling time $34 \mathrm{~h}$ ); and slow growing cholecystokinin-secreting tumor cells of the gut (STC-1 cells) with a doubling time of $54 \mathrm{~h}$ (54).

The fastest and the slowest growing cell lines CM and STC-1 responded very similarly to triciribine. The $\mathrm{IC}_{50}$ values for $\mathrm{CM}$ cells were $12.7 \pm 1.2 \mu \mathrm{mol} / 1$ and even as low as $7.1 \pm 0.8 \mu \mathrm{mol} / 1$ in STC-1 cells. On the other hand moderately fast growing BON cells showed only low sensitivity to triciribine. Marked growth inhibitory effects of triciribine were not observed below doses of as much as $75 \mu \mathrm{mol} / 1$. In vitro concentrations of up to $20 \mu \mathrm{mol} / \mathrm{l}$ triciribine which later could potentially be translated into in vivo studies, did not induce appreciable effects on AKT phosphorylation of BON cells, while in the other two GEP-NET models 'in vivo-like' concentrations led to a strong inhibition of AKT-activity. In other tumor entities there was a clear correlation between baseline levels of p-AKT and sensitivity to AKT inhibitors $(30,55)$. In our case, the most sensitive cell line STC-1, also showed the highest level of baseline AKT phosphorylation, while insensitive BON cells showed the lowest baseline activity of AKT. So, at least partially the observed differences in baseline AKT activity can help to explain the differences in sensitivity to triciribine treatment, while no correlation between doubling time and responsiveness could be observed.

The CAM assay was used to examine the effect of triciribine on GEP-NET cell growth in vivo, which has not been investigated so far. Triciribine treated and tumor bearing CAM showed a significant decrease in tumor volume as compared to untreated controls, indicating substantial activity also in vivo. Moreover, no toxic effects were observed in chicken CAMs at the dose tested during the assay, confirming the good tolerability of the compound.

Employing cancer gene expression profiling we could show that the anti-neoplastic effects of triciribine were partially caused by an induction of cell cycle arrest. Several genes responsible for cell cycle control were altered by triciribine treatment. For instance, cyclin E and CDK2, both being responsible for enhancing the G1/S-phase transition in cells, were downregulated after triciribine treatment. Cyclin D1 was decreased in the immunoblots, as well as the gene expression of the closely interacting CDK4, indicating a G0/S-phase arrest. The association between down-regulation of AKT activity and cyclin D1 expression as well as the importance of AKT-induced cyclin D1 expression as a key mediator of carcinogenic transformation has already been shown $(56,57)$. Moreover, the cyclin-dependent kinase inhibitors p21, p27 and p16 known to influence cell cycle regulation were up-regulated after triciribine treatment. Finally, E2F1, which inhibits the expression of several proteins involved in cell cycle progression, was down-regulated by triciribine, hereby adding to the effect of cell cycle arrest (58). Correspondingly flow cytometry revealed an accumulation of events in G0/G1-phase while the amount of cells in S-transition or G2/M-phase was decreased.
Induction of apoptosis by triciribine was confirmed by flow cytometry, which revealed an increase in the apoptosis-specific subG1-peak and respective changes in the expression pattern of apoptosis associated genes were observed in the gene arrays. Down-regulation of V-AKT and up-regulation of its main inhibitor PTEN both suggest an apoptosis inducing effect, since normally an activated AKT is strongly anti-apoptotic. Other apoptosis inducing gene products were also up-regulated, including APAF1 and BAX, complementing the down-regulation of anti-apoptotic genes like BIRC5 (survivin). Our findings are in line with those of $\mathrm{Hu}$ et al who showed that inhibition of Akt results in a re-expression of p16, which in turn leads to the down-regulation of anti-apoptotic survivin in hepatocellular carcinoma cells (59).

Changes in the expression pattern of PTEN are known to be one of the most common alterations in cancer cells (20). Thus, we performed RT-PCR, looking at levels of PTEN expression in the different GEP-NET models, as this might offer an explanation for the observed differences in triciribine sensitivity of the different GEP-NET models. PTEN levels are higher in BON cells than in CM cells and also, although to a much lesser degree, higher than in STC-1 cells. Given these results, only part of the differences among cell lines in terms of sensitivity to triciribine can be explained. PTEN could cause the differences between BON and CM cells. However, PTEN levels among BON and STC-1 cells are nearly identical, although STC-1 cells are far more sensitive to triciribine treatment.

There are a number of possible additional explanations for the observed effects. PTEN could be mutated in STC-1 cells, leading to a mal-functioning protein, as is the case in many other known cancers (20). Recently, it has been shown, that PI3K has important effects independent of AKT (60), maybe being more pronounced in BON cells. However, a work of Pitt et al investigating the effect of a direct PI3K inhibitor on BON cells led to different results (50). In accordance with our results, it was shown that only very high doses of the PI3K inhibitor were successful in inhibiting the growth of BON cells, thus making it unlikely that AKT-independent effects of PI3K are responsible for the observed resistance of BON cells.

Monotherapy is often not successful at inducing complete remission in cancer. In our case, combination treatment is especially suggestive, since inhibition of AKT has been shown to facilitate induction of apoptosis by other drugs (55). Furthermore, in our study monotherapy with triciribine led to a maximum proliferation reduction of about $60 \%$. Earlier phase I/II studies already indicated that at higher doses triciribine exhibits therapy-limiting adverse reactions (61), emphasizing the idea to use triciribine as a drug for combination treatment, as its synergistic effects are promising, while the monotherapeutic efficacy appears to be rather limited. Thus, we used the already established cytostatic drugs doxorubicin or 5-FU in combination with triciribine. Both drugs were synergistic with triciribine, although more pronounced with 5-FU than with doxorubicin in CM and STC-1 cells.

Next we looked at possible combinations of triciribine together with other targeted cancer therapeutics. The protein mTORC1 is part of the PI3K-AKT-pathway and closely interacts with AKT (62). Moreover, AKT activity is known to determine sensitivity to mTOR inhibitors by regulating cyclin D1 $(63,64)$. Recently, a large multicenter trial was published, showing that 
the mTOR-inhibitor everolimus, as compared with placebo, significantly prolonged progression-free survival among patients with progressive advanced pancreatic neuroendocrine tumors (16). Studies showing that mTORC1 inhibition leads to up-regulation of AKT via loss of feedback inhibition (65) make mTORC1 inhibitors even more attractive as combination partners for triciribine. As a consequence, currently several new compounds are being studied as dual PI3K/mTOR inhibitors $(66,67)$.

When we combined triciribine with the mTORC1 inhibitor, everolimus (RAD-001), we found synergistic anti-proliferative effects, similar to those seen in combinations of triciribine together with 5-FU, although certainly not as strong as the effects seen with triciribine and an IGF-1R inhibitor. One possible explanation could be the finding by Sarbassov et al that prolonged exposure of cells to an mTOR inhibitor finally also leads to an inhibition of mTORC2, thus eventually inhibiting AKT (62). In this respect Jiao et al recently demonstrated that a subset of pancreatic neuroendocrine tumors exhibits genetic alterations of the mTOR pathway. The authors concluded that the mutational status of genes coding for proteins in the mTOR pathway will help to predict clinical response to mTOR inhibition and thus could potentially be used to stratify patients for treatment with mTOR inhibitors (68).

The cancer pathway-specific gene array used in our investigation gave another hint for promising combination therapy. Expression of IGF-1 was $>3.5$-fold elevated in triciribine treated cells. Additional evaluation of IGF-1R expression by qRT-PCR exhibited a concomitant up-regulation of IGF-1R of $\sim 20 \%$, as compared to untreated controls (data not shown). Up-regulation of the IGF-1/IGF-1R system may be interpreted as a kind of mitogenic escape mechanism of neuroendocrine tumor cells to compensate for the triciribine-induced inhibition of AKT-signaling (69). Thus, we hypothesized that additional inhibition of IGF-1/IGF-1R system may help in increasing anti-neoplastic effects of triciribine treatment. Indeed, when triciribine was used together with the IGF-1R tyrosine kinase inhibitor NVP-AEW541, there were highly synergistic effects in CM and STC-1 cells, more pronounced than in any of the other tested combinations. Currently, there is a phase II study in progress, looking at the efficacy of an IGF-1R monoclonal antibody in gastrointestinal neuroendocrine tumors (70). If the results of the study turn out to be positive, we suggest that a combination of triciribine with an IGF-R1 inhibitor for GEP-NETs would be very promising.

In conclusion, we were able to show that AKT inhibition is an attractive target in GEP-NETs. However, the low sensitivity of BON cells indicates that careful selection of appropriate candidates for therapy with an AKT inhibitor is required. Initial screening for PTEN status and activity of AKT in a given GEP-NET might help in taking the appropriate decision. Combination treatments in our study showed promising synergistic effects, thus making AKT inhibition an especially attractive way to increase efficacy of other chemotherapeutic drugs.

\section{Acknowledgements}

We are indebted to Dr K. Kapp of the Institute of Molecular Biology and Bioinformatics, Free University Berlin, Germany, for helping with her expertise in flow cytometry. B. Nitzsche was funded by the Stiftung Urologische Forschung, CharitéBerlin. B. Hoffmann was supported by a grant ('Therapeutic Systems Immunology') of the Bundesministerium für Forschung und Technik (BMBF).

\section{References}

1. Klöppel G, Aurel P and Philipp UH: The gastroenteropancreatic neuroendocrine cell system and its tumors: the WHO Classification. Ann NY Acad Sci 1014: 13-27, 2004.

2. Scarpa A, Mantovani W, Capelli P, et al: Pancreatic endocrine tumors: improved TNM staging and histopathological grading permit a clinically efficient prognostic stratification of patients. Mod Pathol 23: 824-833, 2010.

3. Hemminki $\mathrm{K}$ and $\mathrm{Li} \mathrm{X}$ : Incidence trends and risk factors of carcinoid tumors: a nationwide epidemiologic study from Sweden. Cancer 92: 2204-2210, 2001.

4. Modlin IM, Lye KD and Kidd M: A 5-decade analysis of 13,715 carcinoid tumors. Cancer 97: 934-959, 2003.

5. Norton JA: Surgery for primary pancreatic neuroendocrine tumors. J Gastrointest Surg 10: 327-331, 2006.

6. Moertel CG, Larry KK, Michael JOC and Joseph R: Treatment of neuroendocrine carcinomas with combined etoposide and cisplatin. Evidence of major therapeutic activity in the anaplastic variants of these neoplasms. Cancer 68: 227-232, 1991.

7. Kouvaraki MA, Ajani JA, Hoff P, et al: Fluorouracil, doxorubicin, and streptozocin in the treatment of patients with locally advanced and metastatic pancreatic endocrine carcinomas. J Clin Oncol 22: 4762-4771, 2004.

8. Oberg K, Jelic S and on behalf of the EGWG: Neuroendocrine gastroenteropancreatic tumors: ESMO clinical recommendation for diagnosis, treatment and follow-up. Ann Oncol 20: iv150-iv153, 2009.

9. Rinke A, Müller H-H, Schade-Brittinger C, et al: Placebocontrolled, double-blind, prospective, randomized study on the effect of octreotide LAR in the control of tumor growth in patients with metastatic neuroendocrine midgut tumors: a report from the PROMID Study Group. J Clin Oncol 27: 4656-4663, 2009.

10. Vivanco I and Sawyers CL: The phosphatidylinositol 3-kinaseAKT pathway in human cancer. Nat Rev Cancer 2: 489-501, 2002.

11. Bellacosa A, Kumar CC, Di Cristofano A and Testa JR: Activation of AKT kinases in cancer: implications for therapeutic targeting. Adv Cancer Res 94: 29-86, 2005.

12. Liu P, Cheng H, Roberts TM and Zhao JJ: Targeting the phosphoinositide 3-kinase pathway in cancer. Nat Rev Drug Discov 8: 627-644, 2009.

13. Hopfner M, Schuppan D and Scherubl H: Treatment of gastrointestinal neuroendocrine tumors with inhibitors of growth factor receptors and their signaling pathways: recent advances and future perspectives. World J Gastroenterol 14: 2461-2473, 2008.

14. Yao JC, Ng C, Hoff PM, et al: Improved progression free survival (PFS), and rapid, sustained decrease in tumor perfusion among patients with advanced carcinoid treated with bevacizumab. J Clin Oncol 23: 4007, 2005.

15. Raymond E, Dahan L, Raoul JL, et al: Sunitinib malate for the treatment of pancreatic neuroendocrine tumors. N Engl J Med 364: 501-513, 2011.

16. Yao JC, Shah MH, Ito T, et al: Everolimus for advanced pancreatic neuroendocrine tumors. N Engl J Med 364: 514-523, 2011.

17. Sarbassov DD, Guertin DA, Ali SM and Sabatini DM: Phosphorylation and regulation of $\mathrm{Akt} / \mathrm{PKB}$ by the rictor-mTOR complex. Science 307: 1098-1101, 2005.

18. Stephens L, Anderson K, Stokoe D, et al: Protein kinase B kinases that mediate phosphatidylinositol 3,4,5-trisphosphate-dependent activation of protein kinase B. Science 279: 710-714, 1998.

19. Koseoglu S, Lu Z, Kumar C, Kirschmeier P and Zou J: AKT1, AKT2 and AKT3-dependent cell survival is cell line-specific and knockdown of all three isoforms selectively induces apoptosis in 20 human tumor cell lines. Cancer Biol Ther 6: 755-762, 2007.

20. Trotman LC and Pandolfi PP: PTEN and p53: who will get the upper hand? Cancer Cell 3: 97-99, 2003.

21. Berns K, Horlings HM, Hennessy BT, et al: A functional genetic approach identifies the PI3K pathway as a major determinant of trastuzumab resistance in breast cancer. Cancer Cell 12: 395-402, 2007. 
22. Engelman JA and Janne PA: Mechanisms of acquired resistance to epidermal growth factor receptor tyrosine kinase inhibitors in non-small cell lung cancer. Clin Cancer Res 14: 2895-2899, 2008.

23. She Q-B, Solit D, Basso A and Moasser MM: Resistance to gefitinib in PTEN-null HER-overexpressing tumor cells can be overcome through restoration of PTEN function or pharmacologic modulation of constitutive phosphatidylinositol 3'-kinase/Akt pathway signaling. Clin Cancer Res 9: 4340-4346, 2003.

24. Yu D, Lu C-H, Wyszomierski SL, et al: Preclinical testing of clinically applicable strategies for overcoming trastuzumab resistance caused by PTEN deficiency. Clin Cancer Res 13: 5883-5888, 2007.

25. Wang L, Ignat A and Axiotis CA: Differential expression of the PTEN tumor suppressor protein in fetal and adult neuroendocrine tissues and tumors: progressive loss of PTEN expression in poorly differentiated neuroendocrine neoplasms. Appl Immunohistochem Mol Morphol 10: 139-146, 2002.

26. Gaur P, Samuel S, Bose D, Dallas NA, van Buren G, Gray MJ, Xia L, Fan F, Rashid A, Yao JC and Ellis LM: Establishment and characterization of human midgut carcinoid cell lines: establishing targets for therapy. Ann Surg Oncol 16 (Suppl 1): 81, 2009.

27. Shah T, Hochhauser D, Frow R, Quaglia A, Dhillon AP and Caplin ME: Epidermal growth factor receptor expression and activation in neuroendocrine tumours. J Neuroendocrinol 18: 355-360, 2006

28. Missiaglia E, Dalai I, Barbi S, et al: Pancreatic endocrine tumors: expression profiling evidences a role for AKT-mTOR pathway. J Clin Oncol 28: 245-255, 2010.

29. Pitt SC, Davis R, Kunnimalaiyaan M and Chen H: AKT and PTEN expression in human gastrointestinal carcinoid tumors Am J Transl Res 1: 291-299, 2009.

30. Yang L, Dan HC, Sun M, et al: Akt/protein kinase B signaling inhibitor-2, a selective small molecule inhibitor of Akt signaling with antitumor activity in cancer cells overexpressing Akt. Cancer Res 64: 4394-4399, 2004.

31. National Institute of Mental $\mathrm{H}$ and University of $\mathrm{V}$ : An open label study to investigate the pharmacokinetics and pharmacodynamics of repeat escalating doses of the oral AKT inhibitor GSK2141795 by $18 \mathrm{~F}$ FDG PET analysis in subjects with ovarian cancer. Clinical Trials.gov [Internet]. Bethesda (MD): National Library of Medicine (US). Available from: http://clinicaltrials.gov/ct2/show/ NCT01266954 Identifier NCT01266954.

32. National Institute of Mental $\mathrm{H}$ and University of V: Akt inhibitor MK-2206 in patients with advanced breast cancer who have tumors with a PIK3CA mutation and/or PTEN loss. Clinical Trials.gov [Internet]. Bethesda (MD): National Library of Medicine (US). Available from:http://clinicaltrials.gov/ct2/show/NCT01277757 NLM Identifier NCT01277757.

33. Evers BM, Ishizuka J, Townsend CM Jr and Thompson JC: The human carcinoid cell line, BON. A model system for the study of carcinoid tumors. Ann NY Acad Sci 733: 393-406, 1994.

34. Chang $\mathrm{CH}$, Chey WY, Sun Q, Leiter A and Chang TM: Characterization of the release of cholecystokinin from a murine neuroendocrine tumor cell line, STC-1. Biochim Biophys Acta 1221: 339-347, 1994.

35. Baroni MG, Cavallo MG, Mark M, Monetini L, Stoehrer B and Pozzilli P: Beta-cell gene expression and functional characterisation of the human insulinoma cell line CM. J Endocrinol 161: 59-68, 1999.

36. Gillies RJ, Didier N and Denton M: Determination of cell number in monolayer cultures. Anal Biochem 159: 109-113, 1986.

37. Chou T-C, Motzer RJ, Tong Y and Bosl GJ: Computerized quantitation of synergism and antagonism of taxol, topotecan, and cisplatin against human teratocarcinoma cell growth: a rational approach to clinical protocol design. J Natl Cancer Inst 86: 1517-1524, 1994

38. Decker T and Lohmann-Matthes ML: A quick and simple method for the quantitation of lactate dehydrogenase release in measurements of cellular cytotoxicity and tumor necrosis facto (TNF) activity. J Immunol Methods 115: 61-69, 1988

39. Sutter AP, Maaser K, Barthel B and Scherübl H: Ligands of the peripheral benzodiazepine receptor induce apoptosis and cell cycle arrest in oesophageal cancer cells: involvement of the p38MAPK signalling pathway. Br J Cancer 89: 564-572, 2003.

40. Höpfner M, Sutter AP, Huether A, Schuppan D, Zeitz M and Scherübl H: Targeting the epidermal growth factor receptor by gefitinib for treatment of hepatocellular carcinoma. J Hepatol 41 : 1008-1016, 2004.
41. Fukuda R-I, Tsuchiya K, Suzuki K, et al: Human T-cell leukemia virus type I tax down-regulates the expression of phosphatidylinositol 3,4,5-trisphosphate inositol phosphatases via the NF-kappaB pathway. J Biol Chem 284: 2680-2689, 2009.

42. Gebäck T, Schulz MMP, Koumoutsakos P and Detmar M: TScratch: a novel and simple software tool for automated analysis of monolayer wound healing assays. BioTechniques 46: 265-274, 2009.

43. Zhang G, Gurtu V, Kain SR and Yan G: Early detection of apoptosis using a fluorescent conjugate of annexin $\mathrm{V}$. BioTechniques 23: 525-531, 1997.

44. Engeland MV, Luc JWN, Frans CSR, Bert S and Chris PMR: Annexin V-affinity assay: a review on an apoptosis detection system based on phosphatidylserine exposure. Cytometry 31: 1-9, 1998.

45. Fried J, Arlin Z, Alikpala A, Tan CT and Clarkson B: Kinetic response of human leukemic and lymphoma cells in vivo to combination chemotherapy using flow microfluorometry. Cancer Treat Rep 60: 1937-1946, 1976.

46. Darzynkiewicz Z, Bruno S, Del Bino G, et al: Features of apoptotic cells measured by flow cytometry. Cytometry 13: 795-808, 1992.

47. Nitzsche B, Gloesenkamp C, Schrader M, et al: Novel compounds with antiangiogenic and antiproliferative potency for growth control of testicular germ cell tumours. Br J Cancer 103: 18-28, 2010.

48. Panzuto F, Di Fonzo M, Iannicelli E, et al: Long-term clinical outcome of somatostatin analogues for treatment of progressive, metastatic, well-differentiated entero-pancreatic endocrine carcinoma. Ann Oncol 17: 461-466, 2006.

49. Kunnimalaiyaan M, Kloosterboer $M$ and Chen $\mathrm{H}$ : Carcinoid tumor cell growth suppression by PI3 kinase-Akt pathway inhibition. J Surg Res 130: 262, 2006.

50. Pitt SC, Chen H and Kunnimalaiyaan M: Inhibition of phosphatidylinositol 3-kinase/Akt signaling suppresses tumor cell proliferation and neuroendocrine marker expression in GI carcinoid tumors. Ann Surg Oncol 16: 2936-2942, 2009.

51. Martin-Manso G, Galli S, Ridnour LA, Tsokos M, Wink DA and Roberts DD: Thrombospondin 1 promotes tumor macrophage recruitment and enhances tumor cell cytotoxicity of differentiated U937 cells. Cancer Res 68: 7090-7099, 2008.

52. Muise-Helmericks RC, Grimes HL, Bellacosa A, Malstrom SE Tsichlis PN and Rosen N: Cyclin D expression is controlled posttranscriptionally via a phosphatidylinositol 3-kinase/Akt-dependent pathway. J Biol Chem 273: 29864-29872, 1998.

53. Von Wichert G, Haeussler U, Greten FR, et al: Regulation of cyclin D1 expression by autocrine IGF-I in human BON neuroendocrine tumour cells. Oncogene 24: 1284-1289, 2004

54. Hopfner M, Sutter AP, Gerst B, Zeitz M and Scherubl H: A novel approach in the treatment of neuroendocrine gastrointestinal tumours. Targeting the epidermal growth factor receptor by gefitinib (ZD1839). Br J Cancer 89: 1766-1775, 2003.

55. De Feo-Jones D, Barnett SF, Fu S, et al: Tumor cell sensitization to apoptotic stimuli by selective inhibition of specific Akt/PKB family members. Mol Cancer Ther 4: 271-279, 2005.

56. Ouyang W, Luo W, Zhang D, et al: PI-3K/Akt pathway-dependent cyclin D1 expression is responsible for arsenite-induced human keratinocyte transformation. Environ Health Perspect 116: 1-6, 2008.

57. Parekh P, Motiwale L, Naik N and Rao KVK: Downregulation of cyclin D1 is associated with decreased levels of p38 MAP kinases, Akt/PKB and Pak1 during chemopreventive effects of resveratrol in liver cancer cells. Exp Toxicol Pathol 63: 167-173, 2011.

58. Johnson DG and Walker CL: Cyclins and cell cycle checkpoints. Annu Rev Pharmacol Toxicol 39: 295-312, 1999.

59. $\mathrm{Hu} \mathrm{H}, \mathrm{Li} \mathrm{Z}$, Chen J, et al: P16 reactivation induces anoikis and exhibits antitumour potency by downregulating Akt/survivin signalling in hepatocellular carcinoma cells. Gut 60: 710-721, 2011.

60. Vasudevan KM, Barbie DA, Davies MA, et al: AKT-independent signaling downstream of oncogenic PIK3CA mutations in human cancer. Cancer Cell 16: 21-32, 2009

61. Hoffman K, Holmes FA, Fraschini G, et al: Phase I-II study: triciribine (tricyclic nucleoside phosphate) for metastatic breast cancer. Cancer Chemother Pharmacol 37: 254-258, 1996.

62. Sarbassov DD, Ali SM, Sengupta S, et al: Prolonged rapamycin treatment inhibits mTORC2 assembly and Akt/PKB. Mol Cell 22: $159-168,2006$.

63. Gera JF, Mellinghoff IK, Shi Y, et al: AKT activity determines sensitivity to mammalian target of rapamycin (mTOR) inhibitors by regulating cyclin D1 and c-myc expression. J Biol Chem 279: 2737-2746, 2004. 
64. Dal Col J and Dolcetti R: GSK-3beta inhibition: at the crossroad between Akt and mTOR constitutive activation to enhance cyclin D1 protein stability in mantle cell lymphoma. Cell Cycle 7: 2813-2816, 2008.

65. O'Reilly KE, Rojo F, She Q-B, et al: mTOR inhibition induces upstream receptor tyrosine kinase signaling and activates Akt. Cancer Res 66: 1500-1508, 2006.

66. Zou Z-Q, Zhang X-H, Wang F, et al: A novel dual PI3Kalpha/ mTOR inhibitor PI-103 with high antitumor activity in non-small cell lung cancer cells. Int J Mol Med 24: 97-101, 2009.

67. Liu T-J, Koul D, La Fortune T, et al: NVP-BEZ235, a novel dual phosphatidylinositol 3-kinase/mammalian target of rapamycin inhibitor, elicits multifaceted antitumor activities in human gliomas. Mol Cancer Ther 8: 2204-2210, 2009.
68. Jiao Y, Shi C, Edil BH, et al: DAXX/ATRX, MEN1, and mTOR pathway genes are frequently altered in pancreatic neuroendocrine tumors. Science 331: 1199-1203, 2011.

69. Hopfner M, Baradari V, Huether A, Schofl C and Scherubl H: The insulin-like growth factor receptor 1 is a promising target for novel treatment approaches in neuroendocrine gastrointestinal tumours. Endocr Relat Cancer 13: 135-149, 2006.

70. National Institute of Mental $\mathrm{H}$ and University of V: Multicenter study of IMC-A12 in combination with depot octreotide in patients with carcinoid or islet cell cancer. Clinical Trials.gov [Internet]. Bethesda (MD): National Library of Medicine (US). 2000- [cited 2009 Aug 10]. Available from: http://clinicaltrials.gov/ct2/show/ NCT00781911 NLM Identifier NCT00781911. 